\title{
Psychiatric drug promotion and the politics
}

\section{of neoliberalism}

\section{JOANNA MONCRIEFF}

\begin{abstract}
Summary The pharmaceutical
industry has popularised the idea that many problems are caused by imbalances in brain chemicals. This message helps to further the aims of neoliberal economic and social policies by breeding feelings of inadequacy and anxiety. These feelings in turn drive increasing consumption, encourage people to accept more pressured working conditions and inhibit social and political responses.
\end{abstract}

\section{Declaration of interest None.}

Despite the fact that objective measures show that health is improving, people in the Western world are taking more prescription drugs than ever before. A substantial and rising proportion of these are for mental disorders and this has led some observers to talk of an 'epidemic of psychological disorders' (Hamilton, 2003). In the UK the use of antidepressants increased by $234 \%$ in the 10 years up to 2002 (National Institute for Clinical Excellence, 2004). In the USA $11 \%$ of women and $5 \%$ of men now take antidepressants (Stagnitti, 2005). This development has coincided with the occurrence throughout the world of political and social trends that are sometimes referred to as 'neoliberalism'. I suggest that the model of distress that underpins the promotion of psychiatric drugs may be a useful adjunct to these policies.

Pharmaceutical company publicity frequently refers to chemical imbalances as the putative basis of mental disorders. For example, the following discussion can be found on the Pfizer website (http:// www.geodon.com/s_WhatCauses.asp, last accessed 6 February 2006):

'What causes schizophrenia?'

'No one knows the exact causes of schizophrenia. . . . Imbalances of certain chemicals in the brain are thought to lead to symptoms of the illness. Medicine plays a key role in balancing these chemicals.

The following comments can be found on the Eli Lilly website (http://www.prozac.com/ how_prozac/how_it_works.jsp? reqNavId= 2.2, last accessed 6 February 2006):

'Depression is not fully understood, but a growing amount of evidence supports the view that people with depression have an imbalance of the brain's neurotransmitters, the chemicals that allow nerve cells in the brain to communicate with each other. Many scientists believe that an imbalance in serotonin may be an important factor in the development and severity of depression.'

This idea is a popular version of the longstanding psychiatric model of mental disorder as arising from potentially identifiable deviations from 'normal' biological functioning. However, whereas traditionally this model had a relatively limited application to severe mental disorders, the activities of the pharmaceutical industry in recent years have greatly expanded its application. Disease awareness campaigns for depression, social anxiety disorder, generalised anxiety disorder, posttraumatic stress disorder, attention-deficit hyperactivity disorder and premenstrual dysphoric disorder have been wholly or partly funded by drug companies and they have sponsored research into compulsive buying disorder and 'preventive treatment' for psychosis. The effect of these activities has been to increase the number of people who define themselves as psychiatrically ill and to create the impression that the biochemical basis of psychiatric disorders is well established (Rose, 2004). For example, the well-informed public (e.g. specialist journalists) has been shocked to hear that research has not established that serotonin abnormality is the cause of depression. A recent paper demonstrates why this is so by exposing the gap between the simplistic and confident assertions found in promotional literature (such as those quoted above) and the inconsistent and tenuous nature of the findings of research into the links between serotonin and depression (Lacasse \& Leo, 2005).

How is it possible that society has reached a situation in which 'compulsive buying disorder' does not seem an absurdity and academic papers can discuss its biochemical basis (Bullock \& Koran, 2003)? The answer may lie in the convergence of the efforts of the pharmaceutical industry with wider political interests.

Neoliberal policies, which date from the late 1970 s, are designed to facilitate the expansion of activities of private corporations through deregulation and privatisation. Deregulation refers to reduced state restrictions on trade, capital flows and business practices. A massive transfer of wealth from the public sector to the private sector has occurred worldwide since the 1980s and with it there has been a 'historic transfer of political authority from the state to the private market' (Hamilton, 2003: p. 17). In addition, the principles of the market have been imported into the remaining public enterprises, such as the National Health Service, to foster competition and shape them in readiness for sale to private providers (Price et al, 1999).

Increased commercial activity demands increased consumer spending and deregulation allows industry to increase the levels of exploitation of its workforce. If people are to cooperate with this situation, they must be persuaded that the system is morally good, or at least that it is morally neutral. To this end neoliberalist thought portrays 'market forces' as natural, inevitable and unrestrainable, and as exempt from normal consideration with regard to the exploitation of people or the environment. Therefore the guilt that would normally arise from excessive consumption or profiteering is suppressed (Richards, 1989). In this context the values of individualism, competition and consumerism can be praised and policies justified by appealing to 'efficiency' and 'consumer choice'.

The deregulation of business and the decline in state welfare provision have led to growing inequality throughout the world, both within and between countries. This polarisation between rich and poor has occurred rapidly and very visibly, thanks to the increasing spread of different forms of media. For example, in the USA in the 1980 s the top $10 \%$ of the population increased their income by $16 \%$, and the top $1 \%$ increased their income by $50 \%$. 
In contrast, the bottom $10 \%$ lost $15 \%$ of their income (Phillips, 1990). Alongside this growing polarisation of wealth most people are working more intensely for longer hours, and have poorer working conditions and little job security. Unemployment and low wages are endemic, and health inequalities are growing.

Neoliberal economic policies have been accompanied by increasingly authoritarian social policies. Rates of imprisonment have increased steadily in many Western countries. In the USA, $1.3 \%$ of the male population and almost $5 \%$ of the Black male population are now in prison (Bureau of Justice, 2005). In the UK, legislation in recent years has introduced child curfews, parenting orders and the Anti-Social Behaviour Order (ASBO), and looks set to increase the use of compulsion in the community for psychiatric patients. These measures can be seen as attempts to police the consequences of economic policies by controlling and excluding the minority of Western populations that are the victims of the dismantling of the welfare state and the low-wage economy.

The propagation of the chemical imbalance theory provides a more subtle means of social control, and supports the neoliberal values of competitiveness and consumerism. Hamilton (2003) has pointed out that the system works by encouraging people always to be dissatisfied and to want more. He describes modern consumers as being in a 'permanent state of unfulfilled desire' (Hamilton, 2003: p. 87). The chemical imbalance theory implies that there is a normal or ideal neurochemical state against which everyone can be measured. As the boundaries of disease are pushed out, a large proportion of the population are encouraged to be dissatisfied with themselves and to 'rectify' the state of their brain chemistry. People are encouraged to aspire to be something different from themselves, in their emotional lives as well as in their material lives. Individual consumption - in this case of pharmaceuticals - is presented as the means of achieving this.

However, instead of bringing resolution, people are not easily satisfied, as with material consumption. The need for medication only confirms their feelings of inferiority and anxiety. These feelings are

JOANNA MONCRIEFF, MBBS, BMedSci, MSc, MD, Department of Mental Health Sciences, University College London, Wolfson Building, 48 Riding House Street, London WIN 8AA, UK. E-mail: j.moncrieff@ucl.ac.uk

(First received 14 September 2005, final revision 15 November 2005, accepted 30 November 2005)

debilitating and they help both to create the dissatisfaction that drives consumerist behaviour and to produce a state of mind that is necessary for an increasingly competitive working environment. A population that feels inadequate is more vulnerable to manipulation by advertising and less able to resist increasing demands from employers. Feelings of inadequacy also generate support for authoritarian social policies and right-wing political groups (Hamilton, 2003).

Critics of psychiatry have long pointed out that locating the source of problems in individual biology - 'blaming the brain' - impedes exploration of social and political issues. It prevents serious consideration of the way in which economic imperatives, such as the need to tolerate poor working conditions and the discipline of the school system, help to define certain behaviours as pathological. It also obscures the effects of social factors, such as overwork and increased competition, on mental well-being. If people are permanently preoccupied with their mental health, they are less able to challenge social conditions and to fight for alternative values. The widening application of psychiatric disease theory by the pharmaceutical industry therefore not only helps to expand markets for psychotropic drugs but also helps to create conditions in which neoliberal policies can thrive and in which resistance to them is curtailed.

However, neoliberalism has also created opportunities and paradoxes. Consumer participation has democratised services, increased access to information and challenged the hegemony of professionals. Consumer groups have led the way in criticising the pharmaceutical industry and monitoring and publicising its activities. Examples include the Alliance for Human Research Protection (http:// www.ahrp.org), Corpwatch (http:// www.corpwatch.org) and Public Citizen (http://www.citizen.org) in the USA, Adverse Psychiatric Reactions Information
Link (http://www.april.org.uk), Health Which (http://www.which.co.uk) and Social Audit (http://www.socialaudit.org.uk) in the UK, and Healthy Skepticism (http:// healthyskepticism.org) in Australia. A debate has started within medicine about the relationship of the profession with the pharmaceutical industry but disentangling the two still has far to go. The training of students and junior doctors needs to address both the question of the pharmaceutical industry's influence on research and the compromising nature of drug-company hospitality. Doctors must also become aware of the political implications of the current epidemic of psychotropic drug prescribing, especially since they are well placed to help to apply the brakes.

\section{REFERENCES}

Bullock, K. \& Koran, L. (2003) Psychopharmacology of compulsive buying. Drugs Today, 39, 695-700.

Bureau of Justice (2005) Statistics, June 2004. Washington, DC: Bureau of Justice. http:// www.ojp.usdoj.gov/bjs/prisons. htm

Hamilton, C. (2003) Growth Fetish. Crow's Nest: Allen \& Unwin.

Lacasse, J. R. \& Leo, J. (2005) Serotonin and depression: a disconnect between the advertisements and the scientific literature. PLoS Medicine, 2, e392, doi: 10.1371/journal.pmed.0020392

National Institute for Clinical Excellence (2004) The Treatment of Depression in Primary and Secondary Care. London: NICE.

Phillips, K. (1990) The Politics of Rich and Poor. New York: Random House.

Price, D., Pollock, A. \& Shaoul, J. (1999) How the World Trade Organisation is shaping domestic policies in health care. Lancet, 354, 1889-1991.

Richards, B. (1989) Visions of freedom. Free Associations, 16, 31-42.

Rose, N. (2004) Becoming neurochemical selves. In Biotechnology, Commerce and Civil Society (ed. N. Stehr), pp. 89-128. New Brunswick, NJ: Transaction Publishers.

Stagnitti, M. (2005) Antidepressant Use in the US Civilian Non-Insitutionalised Population, 2002. Statistical Brief \#77. Rockville, MD: Medical Expenditure Panel, Agency for Healthcare Research and Quality. http: // www.meps.ahrq.gov/papers/st77/stat77.pdf 